\title{
COVID-19, Violent Crime, and Domestic Violence: An Exploratory Analysis
}

\author{
Kim Lersch ${ }^{1}$ (D) Timothy C. Hart ${ }^{2}$
}

Received: 20 August 2021 / Accepted: 20 February 2022 / Published online: 5 March 2022

(c) The Author(s), under exclusive licence to Springer Nature Switzerland AG 2022

\begin{abstract}
As the world continues to struggle with the effects of the COVID-19 pandemic, there has been much speculation on the impact of the virus on crime rates, especially violent crime and domestic violence. Disruptions in the patterns of daily, routine activities of life caused by lockdowns have been linked to changes in opportunities for criminal events, and these opportunities may vary based on the type of crime. The purpose of this paper is to examine the rates of violent interpersonal crime and domestic violence in the State of Florida, USA from 1/1/2020 to 12/31/2020. Using counties as the unit of analysis, the rates for selected violent crimes was predicted based on the differential impact of the COVID-19 virus, controlling for various county-level social vulnerability and health-related factors. Comparisons between violent crime levels in 2019 and 2020 were also made. Under opportunity theory, it was predicted that the level of domestic violence would increase in counties that experienced higher infection rates and deaths from COVID-19. Conversely, it was predicted that interpersonal violence would decrease in counties with greater impacts and restrictions due to the COVID-19 virus. The results suggest that as the COVID-19 death rate increased, incidents of domestic violence decreased. Altruism was proposed as an alternative explanation for this atypical finding.
\end{abstract}

Keywords COVID-19 $\cdot$ Domestic violence $\cdot$ Murder $\cdot$ Aggravated assault $\cdot$ Interpersonal crime

\section{Introduction}

The first case of a new coronavirus, COVID-19, was first reported in the United States on 21 January 2020. Three months later, there were over 1 million cases in the U.S. with more than 57,000 deaths linked to the virus (Hauck et al., 2020). Disturbing headlines emerged, linking the pandemic to a potential mental health crisis. Experts warned of heightened levels of anxiety, depression, and panic as unemployment rates skyrocketed and stay-at-home orders became more and more restrictive, forcing people into isolation (Killgore et al., 2021; Ojimba et al., 2020).

It has been a century since the world has seen such a widespread, deadly pandemic. Many comparisons have been drawn to the influenza pandemic in 1918-1919, when at least 50 million people died worldwide, including over a half

Kim Lersch

klersch@usf.edu

University of South Florida, Tampa, FL, USA

2 University of Tampa, Tampa, FL, USA a million in the U.S. (Stern et al., 2010). Mask requirements, lockdowns, school closures, and curfews were also employed to curb the spread of the so-called "Spanish Flu" (Abrams, 2021; Markel, 2020). Researchers and policy makers studied the impact of these containment strategies on social and economic life, including the occurrence of crime. As noted in a working paper by Abrams (2020), an analysis by the Chicago Department of Health in 1919 reported nearly a 40 percent decrease in crime rates in the city of Chicago when there was a lockdown. Interestingly, Abrams found a similar decline of 35 percent in the first 4 weeks of the COVID19 pandemic in Chicago when compared to the rate for the previous 5 years.

The purpose of this paper is to explore the levels of interpersonal violence (as measured by the rates of homicide and aggravated assault), and domestic violence during $2020{ }^{1}$ Using county-level data from the Uniform Crime Reports (UCR) and submitted to the Florida Department of Law Enforcement, the impact of the COVID-19 virus on reported levels of violent crime will be examined. Specifically, do

\footnotetext{
1 Total reported domestic violence figures are reported annually; As
} of this writing, the 2021 data were unavailable for analysis. 
the positivity rates and death rates for COVID-19 have an impact on the reported rates of interpersonal violence (IV) and domestic violence (DV) when controlling for countylevel demographics?

\section{Literature Review}

As the COVID-19 pandemic began to unfold, a number of researchers began to study the impact on a range of crimes, including street level drug activities (Abrams, 2020; Balmori de la Miyar et al., 2021); residential and commercial burglaries (Felson et al., 2020); "porch piracy," which is the theft of delivered packages to homes (Stickle, 2020); domestic violence (Piquero, et al., 2021; Viero et al., 2021); shootings (Kim \& Phillips, 2021); and other offenses. When the level of criminal activity is viewed in broad strokes, there is widespread agreement that crime decreased during the pandemic. This is especially true if one focuses on calls for service to the police as a measure of crime (Boman IV \& Gallupe, 2020). However, as one digs deeper into the available data, the findings suggest that declines may vary based on the specific type of crime and the type of data analyzed (Ashby, 2020; Stickle \& Felson, 2020).

\section{Theoretical Perspectives: Should Crime Increase, or Decrease?}

In the examination of the impact of COVID-19 on levels of crime, many criminologists have focused on choice-based theories, which include elements of routine activities, crime pattern theory, and opportunity perspectives. Through this lens, it would not be surprising to see reductions in certain types of crimes, especially during pandemic lockdowns. Crime occurs when a motivated offender encounters a suitable target that lacks guardianship (Clarke \& Felson, 1993; Cohen \& Felson, 1979; Felson, 1998; Felson et al., 2020). The precautionary restrictions on the movement of individuals through time and space dramatically altered daily, routine activities. Daytime residential burglaries and larcenies should decrease given that the stay-at-home orders increased the level of guardianship not only for the individual homeowner, but the entire neighborhood (Mohler et al., 2020; Stickle, 2020). Similarly, direct contact predatory crimes like robbery should also drop given the lack of potential targets and motivated offenders on the streets (Hodgkinson \& Andresen, 2020). Locations that would normally serve as attractors for motivated offenders and potential targets, such as bars, restaurants, concerts, schools, shopping malls, etc. were all shut down, which would again point to an expected decrease in crime (Brantingham \& Brantingham, 1991, 2008; Hart et al., 2020).
But what impact would the pandemic have on levels of expressive (or affective) crimes, such as domestic violence, homicides, and assaults? These crimes tend to be more spontaneous, emotional, and impulsive actions that are committed in anger. In the case of domestic violence, opportunity also plays a role as individuals are confined at home for extended periods of time. The more time that people spend together in a high stress environment leads to increased opportunities for arguments and altercations (Nix \& Richards, 2021). One could not escape by going to work, school, or out with friends and family; any activity classified as nonessential was prohibited, including attendance at religious services. Increased levels of guardianship may also increase the reporting of domestic violence, as neighbors and other third parties may hear and/or witness disputes and contact law enforcement (Bullinger et al., 2021; Mohler et al., 2020).

Studies of domestic violence (DV) have reported mixed results, although the consensus of studies suggest that calls for service increased, but arrests and official reports remained stable or declined. DV includes incidents of violence against intimate partners, children, or other household members. Anecdotally, under-reporting of DV may be a serious issue, especially due to the stay-at-home orders. School personnel, such as teachers and principals, are mandated reporters of suspected cases of child abuse. Because of the school closures, it is difficult to say how many cases of DV went undetected during the months of isolation. Similarly, incidents of DV may go unreported if the victim chooses not to summon the police for assistance, or reach out to social service institutions for assistance during this unprecedented time (Kaukinen, 2020).

Piquero and colleagues (Piquero et al., 2020, 2021a, 2021b; Reingle Gonzalez et al., 2020) have written a series of articles exploring impact of COVID-19 on domestic violence, finding an increase in incidents across several geographic areas at least in the first few weeks after the lockdowns were initiated. Similarly, Nix and Richards (2021) found increases in calls to the police for domestic violence in five of the six jurisdictions studied. In a study of the City of Chicago, Bullinger et al., 2021 reported that while domestic violence calls for service increased, officer reports and arrests for DV declined. The researchers argued that the decline in arrests may be linked to several factors, including a COVID-19 outbreak in the Cook County Jail and fewer on-site investigations by law enforcement personnel of allegations due to social distancing.

\section{Opportunity and Violent Crimes During COVID-19}

Opportunity theory would predict that for certain types of violent crime, such as assault, rape, and robbery, reduced levels of interpersonal interaction should lead to a reduction in opportunities for crimes to occur (Abrams, 2020). 
Assaults in one UK police force area declined from the predicted level by 36 percent; the authors concluded that the reduction in assaults was linked to the drop in outdoor activities at retail, recreation, and entertainment venues (Halford et al., 2020). In an analysis of 25 of the largest cities in the U.S., Abrams (2020) found substantial decreases in the level of reported violent crime, especially for robbery, aggravated assault, and simple assault. Similarly, in a study of crime rates in 31 cities that controlled for seasonal variations, it was reported that violent crimes tended to decrease in the first months following the implementation of stay-at-home orders. As restrictions were lifted, violent crime peaked during the summer and fall months. The authors argue that this finding lends support to routine activities/opportunity theory, as violent crime increased with greater levels of mobility of potential victims and offenders through time and space (Lopez \& Rosenfeld, 2021).

Results of other studies have been mixed. In an examination of the impact of the virus on a number of different crime types in Vancouver, Canada, there was no significant change in the level of violent crime during the first months of the lockdowns (Hodgkinson \& Andresen, 2020). Other studies have an found increase in aggravated assaults, but no change in murders or shootings (Abrams, 2020). Similarly mixed impacts were found in Los Angeles, where incidents of battery decreased, but no changes were found in the rates of aggravated assault and homicide (Campedelli et al., 2020). In Buffalo, NY, USA, increases in the number of non-fatal and gang-related shootings were found, as well as a temporary increase in the number of fatal shootings (Kim \& Phillips, 2021). Finally, while no empirical data were provided, researchers cautioned against the possibility of an increase in murder-suicides given several factors, such as increases in sales for guns and alcohol coupled with high levels of stress and loneliness during the months of containment (Joiner et al., 2020).

\section{Purpose of the Present Study}

Previous research on the relationship between the pandemic and crime tends to make the assumption that the impact of COVID-19 was consistent across the areas of study. Comparisons have been made between crime rates before and after March, 2020 with little or no consideration that the impacts of COVID-19 may vary based on the positivity rate and death rate at the local level. In the state of Florida, areas with more cases and deaths from COVID-19 tended to impose more stringent restrictions and mandate greater enforcement than locations with fewer cases. For example, Miami-Dade county reported the highest number of COVID19 cases $(298,873)$ and deaths $(4,188)$ in 2020 . During this time frame, the county extended the local state of emergency declaration initially made on March 12, 2020 a total of 34 times, and issued nearly 60 additional emergency orders, guides, and amended policies. And this did not include any additional restrictions imposed by municipalities, such as the City of Miami. Conversely, there were 10 counties that issued 2 or fewer extensions and/or emergency orders. The restrictions varied greatly based on the severity of the pandemic in local jurisdictions (Institute for County Government, 2020).

This study adds to the growing body of literature on the relationship between COVID-19 and crime by considering the local COVID-19 impact on rates of interpersonal violence and domestic violence. Following opportunity theory, it is expected that rates of domestic violence would increase in areas with greater COVID-19 impact. Higher infection rates would lead to extensions of stay-at-home orders, thereby increasing the time that family members must remain in lockdown. Conversely, it is anticipated that rates of interpersonal violence would decrease in counties with significantly higher COVID-19 impacts. As infection rates increase, additional restrictions on mobility would limit opportunities for interpersonal violence as bars, restaurants, and other entertainment venues would be closed for longer periods of time.

\section{Method}

\section{Overview of the State of Florida, U.S.}

The state of Florida is in the southeastern U.S., covering a total area of 65,758 square miles. On April 1, 2020, the state's population was estimated at over 21 million residents, making it the third most populous state behind California and Texas. According to the U.S. Census Bureau (2019), 77.3 percent of residents are white, 16.9 percent are Black, and 26.4 percent identify as Hispanic or Latino. The median household income was estimated to be $\$ 55,660$ (based on 2015-2019 data). Under normal conditions, the state can anticipate nearly an additional 1 million residents during the winter months, when "snowbirds" from Canada, northern states, and other areas travel to enjoy Florida's mild winter climate (Erisman, 2021). This influx of residents did not occur in 2020, as non-essential travel was banned.

Known internationally for its beaches, the state's economy is highly dependent upon tourism, more so than any other state in the U.S. Many workers in Florida are employed in the Accommodation and Food Services industry. As of February 2020, it was estimated that 1.3 million people were employed in jobs related to tourism, or 14.2 percent of the state's working population (Walton, 2019). Even in the best of times, hospitality workers have the lowest average annual wages. The hospitality industry was particularly hard-hit during the pandemic, as stay at home orders were initiated 
and businesses were forced to close. According to Florida's Office of Economic and Demographic Research, the change in the unemployment rate was "breathtaking:" in the span of just a few months, the unemployment rate sharply increased from nearly a 50 year low to a 50 year high (Florida Legislature Office of Economic \& Demographic Research, 2020).

With respect to administrative boundaries, the state of Florida is divided into 67 counties that vary greatly in population density, culture, and history. There are five counties (Miami-Dade, Broward, Palm Beach, Hillsborough and Orange) that have populations greater than 1 million residents. The most populated county (Miami-Dade) has nearly 2.7 million residents; conversely, Liberty County is home to just over 8,000 residents. While some areas in Florida contain major urban areas (i.e., Miami, Orlando, Tampa, Jacksonville, etc.) other areas have far fewer residents. According to the Florida Department of Health (n.d.), there are 30 counties in Florida that are defined as rural, which is defined as a county that has a population density of less than 100 persons per square mile. ${ }^{2}$

\section{The Spread of COVID-19 in the State of Florida, USA}

Florida's Governor Ron DeSantis ${ }^{3}$ reported the first two cases of the coronavirus on March 1, 2020. Within just a few days, the first deaths were reported. A state of emergency was declared on March 9th, 2020. While local governments in larger urban areas (e.g., Tampa and Miami) immediately began to impose various restrictions on the size of social gatherings and business hours of operation, a statewide order to shut down all bars and nightclubs was issued on March 17, 2020. On this date, there were 261 cases of COVID-19 in Florida. Three days later, Governor DeSantis closed all restaurants for indoor dining; only take-out and delivery options were available. By April 1st, there were over 5,000 cases and 60 deaths in the state, prompting the Governor to issue a state-wide stay at home order (Sunderland, 2020). Florida was one of the last states in the U.S. to impose state-wide restrictions (Speck, 2020).

\footnotetext{
2 http://www.floridahealth.gov/programs-and-services/communityhealth/rural-health/_documents/rual-counties-2000-2010.pdf.

${ }^{3}$ In the USA, a governor is the highest-ranking official in a state and essentially serves as the chief executive officer. Governors are granted a great deal of power, especially during times of emergency. A governor may issue executive orders, which are legal mandates that are made without going through a lengthy approval process. Governors have a great deal of discretion in issuing an executive order. With respect to COVID-19, some governors issued very conservative orders restricting the behavior of citizens, while others (including Florida) adopted more liberal mandates. For more information on the powers of governors, please see https://www.nga.org/governors/powers-and-authority/.
}

The stay-at-home order mandated that "all persons in Florida shall limit their movements and personal interactions outside of their home to only those necessary to obtain or provide essential services or conduct essential activities (State of Florida, 2020)." Schools and universities shifted to fully on-line learning, and employers scrambled to find ways for workers to continue their efforts at home. Any business not classified as essential was forced to close, such as hair and nail salons, fitness centers, bars, movie theaters, theme parks, many retailers, etc. Nursing homes and hospitals were closed to visitors and elective surgeries were canceled. Unemployment rates soared; more than one million Florida residents had filed for unemployment benefits by April 23rd (Sunderland, 2020).

While Florida was one of the last states to impose statewide restrictions, it was also one of the first states to begin the process of reopening. Phase One began in early May, 2020 with the opening of Florida's state park system; allowing elective surgeries to be performed; and permitting restaurants to operate at $25 \%$ capacity for indoor seating (WFLA Staff, 2020). Phase 2 started a month later, allowing for restaurants to increase indoor seating to $50 \%$. Several other businesses were allowed to re-open with various restrictions, including bars, movie theaters, concert venues, and other entertainment businesses, tattoo shops, massage parlors, etc. The launch of Phase 2 continued even though the number of COVID-19 cases continued to rise. Finally, Phase 3 was issued on September 25th, 2020, which allowed restaurants and other businesses to operate at full capacity. The Governor's order also limited the ability of local governments to curtail activities. For example, some cities and counties had mandated more stringent restrictions on businesses and citizens than the State because of their higher, localized infection rates. This order banned local governments from issuing their own guidelines, although some businesses and counties defied the Governor's order and continued with stricter mandates (Lisciandrello, 2020; Winchester, 2021).

\section{Data and Measures}

\section{Dependent Variables}

Four dependent variables were used in the current study: the rate of interpersonal violent crime; the rate of domestic violence; and the percent change in the rates of interpersonal violence and domestic violence from 2019 to 2020.

Interpersonal violent crime is defined in this study as the total number of aggravated assaults, ${ }^{4}$ and homicides for each

\footnotetext{
${ }^{4}$ FLDE includes aggravated stalking in the annual aggravated assault data they publish by county.
} 
Table 1 Descriptive statistics for Florida counties $(N=67)$

\begin{tabular}{lrrrr}
\hline Measures & Min & Max & \multicolumn{1}{l}{$M$} & \multicolumn{1}{l}{$S D$} \\
\hline Dependent variables & & & & \\
Interpersonal violent crime rate (Log) & 4.25 & 6.93 & 5.54 & 0.50 \\
Interpersonal violent crime rate (Pct. change) & -0.94 & 2.98 & 0.16 & 0.64 \\
Domestic violence rate & 103.53 & 1242.24 & 524.76 & 241.31 \\
Domestic violence rate (Pct. change) & -0.55 & 0.85 & -0.01 & 0.19 \\
Independent variables & & & & \\
COVID-19 positivity rate (Log) & 8.09 & 9.70 & 8.71 & 0.32 \\
COVID-19 death rate (Log) & 3.52 & 6.04 & 4.62 & 0.47 \\
Control variables & & & & \\
Social vulnerability Index (SVI) & & & & \\
Theme 1 (socioeconomic status) & 0.11 & 3.90 & 1.99 & 1.02 \\
Theme 2 (household composition and disability) & 0.55 & 2.88 & 1.98 & 0.45 \\
Theme 3 (minority status and language) & 0.09 & 2.00 & 0.99 & 0.54 \\
Theme 4 (household type and transportation) & 0.24 & 3.67 & 1.97 & 0.86 \\
Health rankings (z-scores) & & & & \\
Length of life & -0.92 & 1.50 & -0.01 & 0.46 \\
Quality of life & -0.87 & 0.89 & 0.00 & 0.39 \\
Heath behaviors & -0.42 & 0.40 & 0.00 & 0.21 \\
Critical care & -0.36 & 0.29 & 0.00 & 0.13 \\
Social and economic factors & -0.56 & 0.58 & 0.00 & 0.25 \\
Physical environment & -0.09 & 0.09 & 0.00 & 0.04 \\
Urban or rural (1= Urban) & 0 & 1 & 0.55 & 0.50 \\
\hline
\end{tabular}

Crime rates based on 100,000 per population. COVID-19 positivity and death rates are expressed as transformed (natural $\log$ ) of simple percentages. Changes in the rates of interpersonal violence and domestic violence are based on percent changes in rates from 2019 to 2020 of the 67 counties in Florida. The statewide county report containing this information was downloaded from the Federal Bureau of Investigation's (FBI) Annual Uniform Crime Reports data archive maintained by the Florida Department of Law Enforcement (FDLE). ${ }^{5}$ Each year annual crime rates are released for a specific set of crimes in the U.S. The FDLE collects data from each law enforcement agency within the state of Florida and reports this information to the FBI in accordance with uniform reporting standards established by the US Department of Justice. ${ }^{6}$

The interpersonal violent crime total for each county was converted to a rate (per 100,000 population) based on the county's 2020 estimated population. The rate for homicide and aggravated assault was skewed; thus, a log transformation was performed for regression models that follow. Table 1 contains descriptive statistics for the Florida counties analyzed in the current study and shows that the average (transformed) crime rate for interpersonal violence was 5.54 incidents per 100,000 population $(\mathrm{SD}=0.50)$.

\footnotetext{
5 http://www.fdle.state.fl.us/FSAC/CJAB-Home/Uniform-CrimeReport/Data-Archives.

${ }^{6}$ https://ucr.fbi.gov/additional-ucr-publications/ucr_handbook.pdf.
}

In addition to the number of crimes recorded by police, FDLE also reports the percent change in the crime rates from one year to the next. The percent change in the rate for the aggravated assaults and homicides from 2019 to 2020 was included as a separate dependent variable in the models that follow. On average, the rate of interpersonal violence increased by about $16 \%$ in Florida counties from 2019 to 2020 (SD =0.64), according to the FDLE.

The FDLE also provides data on domestic violence in a separate report. ${ }^{7}$ Data collection on domestic violence falls under Florida Statue 943.1702. For an incident to be reported to FDLE as a domestic violence offense, by definition, it must involve one family or household member against another family or household member. According to the statute, "A family or household member means spouses, former spouses, parents, children, siblings, other family members, cohabitants, and persons who are parents of a child in common regardless of whether they have been married. With the exception of persons who have a child in common, the family or household members must be currently residing or have

\footnotetext{
7 http://www.fdle.state.fl.us/FSAC/CJAB-Home/Uniform-CrimeReport/Data-Archives/UCR-Domestic-Violence.
} 
in the past resided together in the same single dwelling unit" (Florida Department of Law Enforcement, 2017, p. 55).

An offense may be counted in both the summary crimes and in the domestic violence report. That is, a homicide may be included as an offense in the county-wide totals for violent crime and counted separately in the DV report if the homicide involved family members. For this analysis the total DV offenses for each county were summed and a rate was calculated based on the FDLE's population estimates. Domestic violence offenses included the following: murder; manslaughter; rape; fondling; aggravated assault; aggravated stalking; simple assault; threat, intimidation, and stalking. The change in the rate for DV offenses from 2019 to 2020 was included as a separate dependent variable. For the 67 counties analyzed, the average rate of domestic violence was about 525 incidents per 100,000 persons. On average, the domestic violence crime rate decreased in Florida from 2019 to 2020 , by about $1 \%$.

\section{Independent Variables}

Two independent variables were used in the current study: the COVID-19 positivity rate and the COVID-19 death rate. The total number of COVID-19 cases for each Florida county that were recorded from January 2020 through December 2020 were downloaded from the University of South Florida (USF) Libraries, Digital Heritage and Humanities Collections Florida COVID-19 hub. ${ }^{8}$ These data were exported from the Florida Department of Health and archived by USF.

The COVID-19 positivity rate was based on the total positive COVID-19 cases reported in each county. This total included Florida residents in Florida, Florida residents outside Florida, and non-Florida residents in Florida. The COVID-19 death rate was based on the cumulative number of Florida residents with confirmed COVID-19 that died within calendar year 2020. Both the COVID-19 cases and death rate are expressed as percentages and were calculated based on the 2020 county population estimates provided by the FDLE crime data.

As both the COVID-19 positivity rate and the death rate were skewed, a log transformation was applied for the regression models that follow. Table 1 shows that in calendar year 2020, the COVID-19 positivity rate (transformed) ranged across all Florida counties from 8.09 to 9.70 $(M=8.71, \mathrm{SD}=0.32)$. The COVID-19 death rate (transformed) ranged from 3.52 to $6.04(M=4.62, \mathrm{SD}=0.47)$.

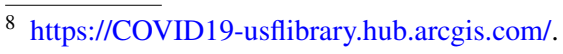

\section{Control Variables}

The Social Vulnerability Index (SVI) produced by the Center for Disease Control and Prevention (CDC) and the Agency for Toxic Substances and Disease Registry (ATSDR) is one of the three control variables used in the current study. According to the CDC, the SVI is intended to assist responders and public health officials in the identification of communities that will most likely need additional support before, during, and after a hazardous event, including disease outbreaks. SVI data are updated every 2 years and may be downloaded for each census tract in the U.S. or for each county. ${ }^{9}$

The SVI is constructed from 15 variables obtained from the U.S. Census Bureau's American Community Survey (ACS), 2014-2018 (5-year) data file. ${ }^{10}$ These variables were grouped into four different Themes according to CDC/ ATSDR guidelines (CDC/ATSDR, 2018) as follows. Theme 1 , an indicator of socioeconomic status, includes the percentage of residents below the poverty level; percent unemployed; income; and percent with no high school diploma. ${ }^{11}$ Theme 2, an indicator of household composition and disability, includes the percent of the population aged 65 or older; percent aged 17 or younger; percentage older than age 5 with a disability; and the percentage of single-parent households. ${ }^{12}$ Theme 3 measures minority status and language and includes the percentage of minority residents, and the percentage that speak English "less than well." 13 Finally, Theme 4 measures housing type and transportation, which includes the percentage of mobile homes, crowding, no vehicle, and group quarters. ${ }^{14}$

\footnotetext{
${ }^{9}$ https://www.atsdr.cdc.gov/placeandhealth/svi/data_documentation_ download.html.

10 The most recent data available are for 2018 .

11 The four indicators used to create Theme 1 demonstrate strong internal consistency $(a=880)$.

12 The reliability of Theme 2 indicators could not be assessed with Cronbach's alpha because the average correlation among them is negative, and reverse coding problematic measures was not possible. Specifically, the percentile rank of counties based on the population of residents under 17 is one of the Theme 2 variables. It is negatively correlated with the percentile rank of counties based on the population of residents over 65 , but positively correlated with the percentile rank of counties based on the population of single-parent households. If the percentile-rank measure of a county's population under 17 was reverse coded, it becomes a measure of those over 16 living in each county. This would be problematic because the measure would now include those not considered vulnerable (i.e., those between 17 and 64 years of age); it would also include those already captured in the "over 65 " vulnerability measure.

13 Since Theme 3 is comprised of two measures, the strength of their correlation was examined and falls within the acceptable range ( $r=.391, p=.001$ ) recommended by Hemphill (2003).

${ }^{14}$ The four indicators used to create Theme 4 demonstrated moderate-to-strong internal consistency $(a=.686)$.
} 
Each of the four SVI Themes described previously are summative measures. To obtain their scores, the 15 vulnerability indicators were calculated for each county as a simple percentage (e.g., the percent of county residence living below the poverty level). Next, the percentile rank was derived from these percentages for each county. Finally, the percentile ranks for all indicators within a Theme were summed to create the Theme's score. For a more detailed discussion of these data, please see the Agency for Toxic Substances and Disease Registry (2020). Descriptive statistics for all four vulnerability Themes used in the current study are presented in Table $1 .{ }^{15}$

County-level health ranking data were also included in the analysis as a second set of control variables. These data were obtained from the Robert Wood Johnson Foundation and the University of Wisconsin Population Health Institute, which provides data for nearly every county in the U.S. on several critical indicators of overall health. The indices are based on a variety of sources, including the Behavioral Risk Factor Surveillance System, the USDA Food Environment Atlas, The Florida Department of Education, and the Environmental Public Health Tracking Network. ${ }^{16}$

Data for each of the six health indicators used in the current study are also presented in Table 1 . They are based on summary Z-scores for every county in Florida and include length of life; quality of life; health behaviors; clinical care; socio/economic factors; and physical environment. The 2020 Florida Data file was used for the analysis that follows. ${ }^{17}$ The six health indicators used in the current study demonstrated strong internal consistency $(a=0.809){ }^{18}$

In addition to the SVI and Health Ranking control variables, the Florida Department of Health classifies counties as either urban or rural based on population density. This classification scheme was used as a third control variable in the analysis that follows. Thirty of Florida's 67 counties $(45 \%)$ were classified as "rural" based on a density of less than 100 persons per square mile. This control variable was coded 1 for urban and 0 for rural.

\footnotetext{
15 Online Appendix 1 provides a correlation matrix showing the bivariate associations between measures of vulnerability, by each of the four Themes.

16 Detailed information about each health indicator, including the measures used to construct them, the data collection source in which each measure was obtained, the year of the data collection program, and weight given to each measure are provided in is available at https://www.countyhealthrankings.org/sites/default/files/media/ document/CHR2020_FL_v2.pdf.

17 https://www.countyhealthrankings.org/app/florida/2021/downl oads.

18 Online Appendix 2 provides a correlation matrix showing the bivariate associations between the six county indicators of health.
}

\section{Analytical Plan}

To explore the research questions, first Pearson's ProductMoment correlation coefficients will be examined for significant relationships. Second, regression models will be examined using ArcMap 10.8. As the data are based on spatial units (i.e., Florida counties), the spatial dependence for each model will be assessed. Ordinary least squares will be run, and standard diagnostics will be used to indicate whether a spatial model (e.g., spatial error, spatial log, or geographically weighted regression) is needed to improve the model.

Given both the exploratory nature of the present study and the small sample size (n-67 counties), a more robust $\mathrm{p}$-value was used in the interpretation of results. The p-value thresholds used conform to common practices in both current governmental publications in our discipline and with recent recommendations by the American Statistical Association (ASA). For example, technical reports like Criminal Victimization, 2000, which is published by the Bureau of Justice Statistics (Bureau of Justice Statistics (BJS), 2021), state that "[F]indings described in this report as increases or decreases passed a test at either (emphasis added) the 0.05 level (95\% confidence level) or 0.10 level (90\% confidence level of significance"(p. 14). Furthermore, in a recent article published in Nature (Amrhein et al., 2019), the authors called for a stop to the use of p-values in the conventional dichotomous way: an effect is present if $p<0.05$ and it is absent if $p>0.05$. Finally, the ASA encourages authors to avoid the conventional use of using only the $p<0.05$ approach to identifying "statistical significance" (Wasserstein \& Lazar, 2016).

\section{Results}

\section{Bi-Variate Correlations}

Bi-variate correlations were examined to associations between the dependent variables, predictor variables, and controls. As shown in correlation matrix contained in Table 2, a significant positive correlation exists between the rate of interpersonal violent crime and the COVID-19 positivity rate $(r=0.27 ; p<0.05)$. However, no significant correlations were found between the COVID-19 positivity rate and the change in the rate of interpersonal violent crime from 2019 to 2020 , the domestic violence rate, or the change in the domestic violence rate from 2019 to 2020.

Furthermore, while no significant correlations were found between the COVID-19 death rate and changes in either the rate of interpersonal violent crime or the domestic violence rate, the county level COVID-19 death rate was weakly correlated with the rate of domestic violence $(r=-0.23$, 
Table 2 Correlation matrix showing bivariate associations between focal variables

\begin{tabular}{lccrl}
\hline & IPV (log) & IPV (change) & DV & DV (change) \\
\hline COVID-19 (pos.) & $\mathbf{0 . 2 7}$ & 0.15 & -0.07 & -0.01 \\
COVID-19 (death) & 0.00 & -0.04 & -0.23 & -0.20 \\
SVI theme 1 & $\mathbf{0 . 2 9}$ & 0.13 & 0.18 & -0.02 \\
SVI theme 2 & 0.03 & -0.13 & 0.13 & -0.14 \\
SVI theme 3 & 0.15 & 0.06 & -0.03 & -0.03 \\
SVI theme 4 & $\mathbf{0 . 3 4}$ & 0.14 & 0.14 & 0.07 \\
Length & $\mathbf{0 . 2 7}$ & 0.04 & 0.18 & -0.15 \\
Quality & $\mathbf{0 . 4 0}$ & 0.18 & $\mathbf{0 . 2 4}$ & -0.15 \\
Health & $\mathbf{0 . 2 5}$ & 0.02 & 0.23 & -0.03 \\
Care & 0.16 & 0.08 & 0.06 & -0.01 \\
Socioeconomics & $\mathbf{0 . 3 3}$ & 0.19 & $\mathbf{0 . 2 9}$ & -0.02 \\
Environment & 0.04 & $\mathbf{0 . 2 5}$ & -0.01 & -0.12 \\
Urban & $\mathbf{- 0 . 2 5}$ & -0.18 & -0.04 & -0.01 \\
\hline
\end{tabular}

Italics $=p<.10 ;$ Bold $=p<.05 ;$ Bold and italics $=p<.01$ $p<0.10)$. This finding was interesting given the direction of the relationship. The COVID-19 death rate was negatively correlated with acts of domestic violence, meaning that as the death rate increased, the rate of domestic violence decreased.

\section{COVID-19 and Interpersonal Violence}

The first research question explored in this analysis focused on the relationship between COVID-19 positivity rates and the rate of interpersonal violence, controlling for social vulnerability and county health characteristics, as well as urbanicity. Results are presented in Table 3 and show that the
Table 3 Summary of ordinary least squares (OLS) regression for variables predicting the rate of interpersonal violence (Model 1) and the change in the interpersonal violence rate from 2019 to 2020 (Model 2) in Florida counties

\begin{tabular}{|c|c|c|c|c|c|c|}
\hline \multirow[b]{3}{*}{ Measures } & \multicolumn{6}{|c|}{ Predicting interpersonal violence } \\
\hline & \multicolumn{3}{|c|}{ Model 1} & \multicolumn{3}{|c|}{ Model 2} \\
\hline & $B$ & SE & $t$ & $B$ & SE & $t$ \\
\hline \multicolumn{7}{|l|}{ Independent variables } \\
\hline COVID-19 positivity rate (Log) & 0.64 & 0.34 & 1.88 & 0.17 & 0.18 & 0.95 \\
\hline COVID-19 death rate (Log) & -0.32 & 0.15 & -2.04 & -0.28 & 0.10 & -2.76 \\
\hline \multicolumn{7}{|l|}{ Control variables } \\
\hline \multicolumn{7}{|l|}{ Social vulnerability index (SVI) } \\
\hline Theme 1 (socioeconomic status) & -0.14 & 0.13 & -1.11 & 0.16 & 0.08 & 1.92 \\
\hline Theme 2 (household composition and disability) & -0.23 & 0.19 & -1.20 & 0.13 & 0.13 & 0.96 \\
\hline Theme 3 (minority status and language) & 0.36 & 0.16 & 2.23 & 0.12 & 0.10 & 1.15 \\
\hline Theme 4 (household type and transportation) & -0.08 & 0.16 & -0.53 & & & \\
\hline \multicolumn{7}{|l|}{ County health (ranked z-scores) } \\
\hline Length of life & 0.46 & 0.22 & 2.10 & 0.24 & 0.15 & 1.54 \\
\hline Quality of life & 0.47 & 0.27 & 1.75 & -0.41 & 0.19 & -2.19 \\
\hline Critical care & -1.04 & 0.85 & -1.23 & -1.09 & 0.54 & -2.00 \\
\hline Socioeconomics & 0.50 & 0.41 & 1.21 & 0.14 & 0.25 & 0.54 \\
\hline Physical environment & -0.04 & 1.47 & -0.02 & -0.85 & 0.94 & -0.90 \\
\hline Urban or rural $(1=$ Urban $)$ & -0.22 & 0.22 & -0.97 & -0.10 & 0.14 & -0.72 \\
\hline Intercept & 2.10 & 2.60 & 0.81 & -0.88 & 1.53 & -0.58 \\
\hline F-statistic & 2.83 & & & 1.79 & & \\
\hline$R^{2}$ & 0.39 & & & 0.30 & & \\
\hline$R^{2} \mathrm{Adj}$ & 0.25 & & & 0.13 & & \\
\hline Jarque-Bera & 4.04 & & & 9.40 & & \\
\hline Koenker (BP) & 15.42 & & & 6.54 & & \\
\hline Moran’s I (Z) & 0.44 & & & -1.38 & & \\
\hline$N$ & 67 & & & 59 & & \\
\hline
\end{tabular}

Significance levels based on one-tailed tests: Italics $=p<.10 ;$ Bold $=p<.05 ;$ Bold and italics $=p<.01$ 
overall model (Model 1$)^{19}$ was significant $(F(12,54)=2.83$, $p<0.001$ ), explaining about $25 \%$ of the variation in the rate of interpersonal violence at the county level. Furthermore, based on the Jarque-Bera test and the Koenker statistic, results indicate that the relationship between the variables did not vary significantly across the study area. A queen's case contiguity spatial weights matrix was used to provide diagnostic statistics that can explore for spatial effects in the model (Chainey, 2021) and the resulting Moran's I value was not significant $(z=0.44, p=0.660)$. Therefore, a spatial regression model was not necessary.

Based on Model 1, the COVID-19 death rate was significant predictor of the rate of interpersonal violent crime $(t(66)=-2.04, p=0.046)$ and the COVID-19 positivity rate was significant at the $90 \%$ confidence level $(t(66)=1.88$, $p=0.066$ ). Although the death rate was negatively associated with the rate of interpersonal violence, the positivity rate was related to the dependent variable in the hypothesized direction.

Results from Model 1 also show that some of the control variables are significant predictors of the interpersonal violent crime rate, including both the Theme 3 vulnerability (i.e., minority status and language; $[t(66)=2.23, p=0.030]$ ) and the length of life measure $(t(66)=2.10, p=0.041)$. It is also significantly related to the quality of life measure $(t(66)=1.77, p=0.089)$ at the $90 \%$ confidence level. In other words, the interpersonal violent crime rate increases at the county level when the value of each of these predictors also increases.

\section{COVID-19 and the Change in Interpersonal Violence, 2019-20}

The second research question explored in this analysis focused on predicting the change in the rates of interpersonal violence from 2019 to 2020 . Results are presented in Model $2^{20}$ and show the data are not a significant fit $(F(12$, $54)=1.11, p=0.372)$. Despite the overall model not fitting the data, the COVID-19 death rate was still inversely related to the change in the rate of interpersonal violence $(t(58)=-2.78, p=0.004)$. In addition, the one of the social

\footnotetext{
19 The variance inflation factor (VIF) score for the healthy behaviors measure exceeded 7.5 in all four models presented below, suggesting a problem with multicollinearity. In response, all four models are estimated with this measure of county health excluded.

${ }^{20}$ In addition to removing the healthy behavior measure (see Footnote 16), the Theme 4 vulnerability measure was removed because of multicollinearity (VIF=8.53). Furthermore, the rate of change in interpersonal violence was identified as an outlier for eight counties. Those counties were removed from the analysis using listwise deletion.
}

vulnerability measures (i.e., Theme 1) was positivity associated with the change in interpersonal violence $(t(58)=1.92$, $p=0.031$ ). Several of the county health measures were also significantly related to the change in interpersonal violence from 2019 to 2020. Results of the Moran's I found no spatial pattern in the distribution of the residuals $(z=-1.38$, $p=0.084)$. Therefore, a spatial regression model was not necessary.

\section{COVID-19 and Domestic Violence}

The third research question explored in this analysis was whether the impact of COVID-19 was related to domestic violence. Specifically, is the COVID-19 positivity and COVID-19 death rates predictors of domestic violence, after controlling for community-level factors? OLS models were used to address these questions and results are presented in Table 4.

Results in Table 4 (Model 3) show that the overall model predicting domestic violence was not significant $(F(12$, $54)=1.47, p=0.167$ ). Despite the overall model not fitting the data, the COVID-19 death rate was still a significant predictor of the domestic violence rate $(t(66)=-2.69$, $p=0.005)$. Neither the COVID-19 positivity rate nor the other control variables were significantly related to the domestic violence rate. The Koenker statistic was significant at the $90 \%$ confidence level, indicating that the relationships modeled were not consistent, either due to non-stationary or heteroskedasticity. A queen's case contiguity spatial weights matrix was used to provide diagnostic statistics that can explore for spatial effects in the model (Chainey, 2021). However, the resulting Moran's I value was not significant $(z=1.33, p=0.201)$.

\section{COVID-19 and the Change in Domestic Violence, 2019-20}

Finally, the change in the rate of domestic violence was modelled and the results are presented in Table 4 (Model 4). The overall reduced model was not significant $(F(12,54)=0.94$, $p=0.520)^{21}$ and none of the predictors were significantly associated with the outcome variable. Furthermore, the Koenker statistic was no longer significant, indicating that the relationship between the variables no longer varied significantly across the study area. The resulting Moran's I value was not significant $(z=-0.05, p=0.480)$, however, indicating a spatial regression model was not necessary.

\footnotetext{
21 The rate of change in domestic violence was identified as an outlier for three counties. Those counties were removed from the analysis using listwise deletion.
} 
Table 4 Summary of ordinary least squares (OLS) regression for variables predicting the rate of domestic violence (Model 3) and the changes in the domestic violence rate from 2019 to 2020 (Model 4) in Florida counties

\begin{tabular}{|c|c|c|c|c|c|c|}
\hline \multirow[b]{3}{*}{ Measures } & \multicolumn{6}{|c|}{ Predicting domestic violence } \\
\hline & \multicolumn{3}{|l|}{ Model 3} & \multicolumn{3}{|l|}{ Model 4} \\
\hline & $B$ & SE & $t$ & $B$ & SE & $t$ \\
\hline \multicolumn{7}{|l|}{ Independent variables } \\
\hline COVID-19 positivity rate ( $\mathrm{Log})$ & -56.08 & 181.91 & -0.31 & 3.71 & 10.06 & 0.37 \\
\hline COVID-19 death rate (Log) & -222.44 & 82.57 & -2.69 & -5.83 & 4.59 & -1.27 \\
\hline \multicolumn{7}{|l|}{ Control variables } \\
\hline \multicolumn{7}{|l|}{ Social vulnerability index (SVI) } \\
\hline Theme 1 (socioeconomic status) & 49.36 & 68.06 & 0.73 & 4.43 & 3.84 & 1.15 \\
\hline Theme 2 (household composition and disability) & -3.30 & 101.55 & -0.03 & 0.82 & 5.75 & 0.14 \\
\hline Theme 3 (minority status and language) & -21.13 & 85.99 & -0.25 & 1.52 & 5.19 & 0.29 \\
\hline Theme 4 (household type and transportation) & 28.43 & 86.40 & 0.33 & 1.20 & 5.07 & 0.24 \\
\hline \multicolumn{7}{|l|}{ County health (ranked z-scores) } \\
\hline Length of life & 60.44 & 117.78 & 0.51 & -6.44 & 6.41 & -1.00 \\
\hline Quality of life & 49.33 & 143.15 & 0.35 & -9.08 & 8.16 & -1.11 \\
\hline Critical care & -175.26 & 452.27 & -0.39 & -28.98 & 26.13 & -1.11 \\
\hline Socioeconomics & 226.65 & 221.05 & 1.03 & 6.08 & 12.53 & 0.49 \\
\hline Physical environment & -350.60 & 785.39 & -0.45 & 8.49 & 44.35 & 0.19 \\
\hline Urban or rural $(1=$ Urban $)$ & 88.13 & 119.10 & 0.74 & -4.03 & 6.94 & -0.58 \\
\hline Intercept & 1866.96 & 1390.29 & 1.34 & -18.27 & 77.59 & -0.24 \\
\hline F-statistic & 1.47 & & & 0.94 & & \\
\hline$R^{2}$ & 0.25 & & & 0.18 & & \\
\hline$R^{2}$ Adj & 0.08 & & & -0.01 & & \\
\hline Jarque-Bera & 0.43 & & & 1.38 & & \\
\hline Koenker (BP) & 20.02 & & & 9.53 & & \\
\hline Moran's I (Z) & 1.33 & & & -0.05 & & \\
\hline$N$ & 67 & & & 64 & & \\
\hline
\end{tabular}

Significance levels based on one-tailed tests: Italics $=p<.10 ;$ Bold $=p<.05 ;$ Bold and italics $=p<.01$

\section{Discussion}

The purpose of this study was to explore potential relationships between the COVID-19 positivity rates and death rates on violent interpersonal crimes and domestic violence when controlling for several demographic variables in the state of Florida. Following the tenets of opportunity theory, it was hypothesized that in areas with greater impacts from COVID-19, levels of domestic violence would increase. Conversely, in areas with lower impacts from the COVID-19 pandemic, levels of interpersonal violence would increase. The results suggested that the local impacts of COVID-19 on violent behavior were an important variable to consider, although this relationship was more complex than anticipated.

In the models predicting interpersonal violence, both the $\log$ of the positivity rate and the log of the death rate were found to be significant predictors, along with several county control variables. Interestingly, the direction of these measures of COVID-19 impact were not consistent. The death rate measure was inversely related to the rate of IPV as well as the change in IPV from 2019-2020. This finding was consistent with opportunity theory; in areas where the virus was more severe the IPV rate declined, suggesting that local residents were avoiding locations that would typically be crime generators. However, the COVID infection rate was positively associated with the rate of IPV. That is, in counties with higher numbers of COVID cases, levels of IPV increased. This result may suggest that citizens may have modified their behaviors based on their perception of the severity of the COVID impact. Higher local death rates may have encouraged motivated offenders and potential targets to curtail their activities, while higher positivity rates may not have been viewed with the same level of trepidation and fear.

With respect to domestic violence, a significant, negative relationship was found between the log of the COVID death rate and the rate of domestic violence. The log of the COVID-19 positivity rate, while not a significant predictor, was also found to be negative. This implies that as the severity of the COVID-19 pandemic increased, levels of domestic 
violence decreased. This finding is counter to routine activities / opportunity theory. In counties with greater impacts of the virus and greater restrictions on mobility, domestic violence levels did not increase, even though the opportunity level increased.

\section{Opportunity or Altruism?}

Opportunity theory is not the only explanation for changes in criminal behavior during emergencies, natural disasters, or other exceptional events. Altruism theories suggest that crime rates may decline or remain relatively stable in the face of uncertainty. Rather than victimizing each other, people may be more likely to act altruistically; this has also been referred to as the 'pulling together' phenomenon (Deisenhammer \& Kemmler, 2021; Hodgkinson \& Andresen, 2020; John et al., 2020).

Media coverage of the global pandemic was nearly impossible to escape. Daily infection and death totals were pushed out to cell phones and social media. The COVID-19 pandemic was the lead story for news outlets around the world. It has been argued that this constant barrage of public health messages may have unintended consequences, including increased anxiety, depression, and fear (Garfin et al., 2020; Sloan et al., 2021; Tsamakis et al., 2021). Fear of an unknown, deadly virus can have a strong impact on behavior, in the same manner that fear of crime can lead to modifications in how one lives one's life. Fear and other emotions can have a dramatic influence on the decision making process, for both the motivated offender and a potential target (Barnum \& Solomon, 2019; Sloan et al., 2021).

In a national survey conducted in the early stages of the pandemic, Sloan and colleagues (2021) explored the impact of the COVID-19 pandemic on levels of personal fear (fear for ones self) and altruistic fear (fear for others). Interestingly, feelings of altruistic fear were strongest for family members; altruistic feelings declined for those outside of the immediate circle of family and friends. Additionally, men tend to express greater levels of atruistic fear for their spouse or significant other. It may be that fear of the COVID-19 virus led to greater feelings of altruism among members of the immediate family, resulting in the decline in rates of domestic violence. While heightened levels of COVID-19 would lead to greater opportunities for domestic violence, the fear brought on by the virus may have led to a culture of altruism and protection rather than one of violence.

\section{Limitations of the Study}

Criminologists have long struggled to find a reliable, valid measure of crime (Hart et al., 2020). This is especially true in these turbulent times associated with the pandemic. As discussed by Bowman IV \& Gallupe (2020), media outlets tend to focus on large cities, and to date there have been no nationally representative self-report studies conducted on the relationship between criminal activities and the lockdowns. Furthermore, researchers are powerless to speed up data reporting such as the National Incident Based Reporting System or modify the timeline in which the Federal Bureau of Investigation releases their official statistics (Boman IV $\&$ Gallupe, 2020). For example, in the present study the annual totals of violent crimes by county were used. A more refined data source that was updated on a bi-weekly basis with greater detail on the specifics of the incident would have been more informative, but those data do not exist. We do the best we can with the available information and carefully consider the limitations of our conclusions.

The results of this study were based on official data reported by law enforcement agencies across the state. As these are crimes known to the police, it is impossible to know what the 'true' level of violence was during this 12 -month period. This is especially true with respect to domestic violence. Acts of domestic violence tend to be underreported, especially among minorities, immigrants, the LGBTQ community, and residents of public housing for fear of being evicted (Addington \& Lauritsen, 2021). In the state of Florida, the arrest of the aggressor in incidents of domestic violence is the preferred action, although the responding officer still has some discretion in the matter (Florida Senate, 2020). Regardless of whether an officer makes an arrest, a report of a domestic violence incident is mandatory for data collection purposes. If an officer decided not to make an arrest, this decision must be justified in the report. This report is then reviewed by the officer's supervisor.

It would not be surprising if incidents of domestic and interpersonal violence would not result in an arrest during a pandemic. Local jails were releasing inmates to prevent the spread of COVID-19 among the incarcerated population (BallotPedia.org, 2020). Households were already under financial strain, and officers may have been less likely to remove a possible financial contributor from the home. One of the true weaknesses of relying on official statistics is that one is unable to discern whether any increase or decrease in the level of reported violence reflects the behavior of the police or the behavior of citizens. Furthermore, given the strain on first responders during this turbulent time, an officer may choose to not file a report of domestic violence. Calls for service for DV may have been false positives, as neighbors (who were also confined to their homes) may have called the police due to loud arguments and not actual cases of DV. This is consistent with opportunity theory, as guardianship increased during confinement periods. It may be that the early call to the police averted an escalation of disagreement to violence.

The reader is also cautioned that this study used macrolevel units of analysis to examine individual-level behavior. 
That is, rates of DV and IPV based on annual reports at the county level were used to explore increases and decreases in violent crimes between individuals. This can result in an ecological fallacy, where behaviors of individuals are predicted based on the county in which one resides. As discussed by Walker, an easy remedy to avoid the ecological fallacy is to only collect data at the individual level. Describing this approach as 'short-sighted,' he goes on to argue that it is sometimes necessary to rely on macro-level data in order to build on our knowledge in the discipline (Walker, 2021). The purpose of this study was to explore for general trends in behavior and not to conduct a causal analysis. Future researchers may wish to dig deeper into this phenomenon to see if stronger conclusions can be made based on datal collected at the individual level.

\section{Future Research Directions}

This study utilized official reports from a single state in the US. As described earlier, Florida was atypical with respect to the restrictions and mandates placed on people and businesses, adopting relatively few constraints. It would be of interest to see if similar results were found in other states that were more restrictive in their response to COVID-19.

It would also be of interest to replicate this study using smaller time increments. The results of the present study were based on annual rates, which missed any subtle increases or decreases in the crime rates as the COVID-19 rates changed over time. For example, the level of crime may have initially decreased when the pandemic began. Given the source of this data, the granular changes that may have occurred over time may be lost.

The findings of this study suggest that as the impact of the COVID-19 virus increased, levels of domestic violence decreased. Further, in counties with higher numbers of COVID cases, levels of IPV increased. These results suggest that it is important to consider the local impact of the virus on levels of violent crime. Future research should include measures of the severity of the pandemic at the local level. Additionally, alternative theories, such as altruism, should be considered. Routine activities / opportunity theories certainly have merit, but when one considers that the impact of the virus is not consistent across study areas other explanations may be warranted.

\section{Conclusion}

The overall effects of COVID-19 are still unfolding. As of this writing, the state of Florida has reported over 62,000 deaths and nearly 4 million cases of COVID-19 (Florida Department of Health, 2021). The Omicron variant has taken center stage, while the country still wrestles with the impacts of the Delta variant. The reader is cautioned that the virus is far from over, and long-term studies may change the way we think about crime and opportunity. In fact, this time is being described as the largest criminological experiment in history (Stickle \& Felson, 2020).

Supplementary Information The online version contains supplementary material available at https://doi.org/10.1007/s43576-022-00049-y.

\section{References}

Abrams, D. S. (2020). COVID and crime: An early empirical look. https://ssrn.com/abstract $=3674032$

Abrams, D. S. (2021). Crime rates dropped in 2020_Just as they did in 1918. Wired. https://www.wired.com/story/crime-rates-dropp ed-in-2020-just-as-they-did-in-1918/

Addington, L., \& Lauritsen, J. L. (2021). Using national data to inform our understanding of family and intimate partner violence victimization: A review of a decade of innovation. Feminist Criminology, 16(3), 304-319.

Amrhein, V., Greenland, S., \& McShane, B. (2019). Scientists rise up against statistical significance. Nature, 567, 305-307. https://doi. org/10.1038/d41586-019-00857-9

Ashby, M. P. J. (2020). Initial evidence on the relationship between the coronavirus pandemic and crime in the United States. Crime Science, 9(1), 1-16. https://doi.org/10.1186/s40163-020-00117-6

BallotPedia.org. (2020). Prison inmate release responses in response to the coronavirus pandemic, 2020. Retrieved August 20 from https://ballotpedia.org/Prison_inmate_release_responses_in_ response_to_the_coronavirus_(COVID-19)_pandemic,_2020\# cite_note-21

Balmori de la Miyar, J. R., Hoehn-Velasco, L., \& Silverio-Murillo, A. (2021). Druglords don't stay at home: COVID-19 pandemic and crime patterns in Mexico City. Journal of criminal justice, 72, N.PAG-N.PAG. https://doi.org/10.1016/j.jcrimjus.2020.101745

Barnum, T. C., \& Solomon, S. J. (2019). Fight or flight: Integral emotions and violent intentions. Criminology, 57(4), 659-686. https:// doi.org/10.1111/1745-9125.12222

Boman, J. H., IV., \& Gallupe, O. (2020). Has COVID-19 changed crime? Crime rates in the United States during the Pandemic. American Journal of Criminal Justice, 45(4), 537-545. https:// doi.org/10.1007/s12103-020-09551-3

Brantingham, P. J., \& Brantingham, P. L. (1991). Environmental Criminology (2nd ed.). Waveland Press.

Brantingham, P. J., \& Brantingham, P. L. (2008). Crime Pattern Theory. In R. Wortley \& L. Mazerolle (Eds.), Environmental criminology and crime analysis. Willan Publishing.

Bullinger, L., Carr, J., \& Packham, A. (2021). Effects of stay-at-home orders on domestic violence. American Journal of Health Economics, 7(3), 249-280.

Bureau of Justice Statistics (BJS). (2021). Criminal victimization, 2020. USGPO.

Campedelli, G. M., Aziani, A., \& Favarin, S. (2020). Exploring the immediate effects of COVID-19 containment policies on crime: An empirical analysis of the short-term aftermath in Los Angeles. American Journal of Criminal Justice. https://doi.org/10.1007/ s12103-020-09578-6

Chainey, S. (2021). Understanding crime: Analyzing the geography of crime. ESRI Press.

Chapter 741 Marriage; Domestic Violence, § Section 29 (2020). https://m.flsenate.gov/statutes/741.29 
Clarke, R., \& Felson, M. (1993). Routine activity and rational choice: Advances in criminological theory volume 5. Transaction Publishers.

Cohen, L., \& Felson, M. (1979). Social change and crime rate trends: A routine activity approach. American Sociological Review, 44, 588-608.

Deisenhammer, E. A., \& Kemmler, G. (2021). Decreased suicide numbers during the first 6 months of the COVID-19 pandemic. Psychiatry Research, 295, 113623. https://doi.org/10.1016/j.psych res.2020.113623

Erisman, R. (2021). A snowbird's florida guide. https://www.floridafor boomers.com/snowbirds-florida-guide/

Felson, M. (1998). Crime and everyday life. Pine Forge Press.

Felson, M., Jiang, S., \& Xu, Y. (2020). Routine activity effects of the COVID-19 pandemic on burglary in Detroit. Crime Science. https://doi.org/10.1186/s40163-020-00120-x

Florida Department of Health. (2021). COVID-19 weekly situation report: State overview. http://ww11.doh.state.fl.us/comm/_partn ers/covid19_report_archive/covid19-data/covid19_data_latest.pdf

Florida Department of Law Enforcement. (2017). Uniform crime reports guide manual. https://www.google.com/url?sa $=\mathrm{t} \& \mathrm{rct}=$ $\mathrm{j} \& \mathrm{q}=\& \mathrm{esrc}=\mathrm{s} \&$ source $=$ web $\& \mathrm{~cd}=\& \mathrm{ved}=2 \mathrm{ahUKEwiVo} 4 \mathrm{KLqa}$ TyAhUCHM0KHR2mApUQFnoECAsQAw\&url=https $\% 3 \mathrm{~A} \%$ 2F\%2Fwww.flrules.org\%2Fgateway\%2FreadRefFile.asp\%3Fref Id\%3D9686\%26filename\%3DUCR\%2520Guide\%2520Manual\% 25202017.pdf\&usg=AOvVaw3DhwKVIdUJg_YKm8JtyFZ

Florida Legislature Office of Economic and Demographic Research. (2020). Florida: An economic overview. http://edr.state.fl.us/conte nt/presentations/economic/FlEconomicOverview_12-30-20.pdf

Garfin, D. R., Silver, R. C., \& Holman, E. A. (2020). The novel coronavirus (COVID-2019) outbreak: Amplification of public health consequences by media exposure. Health Psychology, 39(5), 355-357.

Halford, E., Dixon, A., Farrell, G., Malleson, N., \& Tilley, N. (2020). Crime and coronavirus: Social distancing, lockdown, and the mobility elasticity of crime. Crime Science, 9(1), 1-12. https:// doi.org/10.1186/s40163-020-00121-w

Hart, T., Lersch, K. M., \& Chataway, M. (2020). Space, time \& crime (5th ed.). Carolina Academic Press.

Hauck, G., Gelles, K., Bravo, V., \& Thorson, M. (2020). Three months in: A timeline of how COVID-19 has unfolded in the U.S. USA Today. https://www.usatoday.com/in-depth/news/nation/2020/ 04/21/coronavirus-updates-how-covid-19-unfolded-u-s-timel ine/2990956001/

Hodgkinson, T., \& Andresen, M. A. (2020). Show me a man or a woman alone and I'll show you a saint: Changes in the frequency of criminal incidents during the COVID-19 pandemic. Journal of Criminal Justice, 69, N.PAG-N.PAG. https://doi.org/10.1016/j. jcrimjus.2020.101706

Institute for County Government. (2020). County COVID-10 policies \& orders. Florida Institute for County Government. Retrieved 12/19/21 from https://flicg.org/county-by-county-covid-19-infor mation/

John, A., Pirkis, J., Gunnell, D., Appleby, L., \& Morrissey, J. (2020). Trends in suicide during the covid-19 pandemic. BMJ, 371, m4352. https://doi.org/10.1136/bmj.m4352

Joiner, T. E., Lieberman, A., Stanley, I. H., \& Reger, M. A. (2020). Might the COVID-19 pandemic spur increased murder-suicide? Journal of Aggression, Conflict \& Peace Research, 12(3), 177182. https://doi.org/10.1108/JACPR-05-2020-0502

Kaukinen, C. (2020). When stay-at-home orders leave victims unsafe at home: Exploring the risk and consequences of intimate partner violence during the COVID-19 pandemic. American Journal of Criminal Justice, 45(4), 668-679. https://doi.org/10.1007/ s12103-020-09533-5
Killgore, W. D. S., Cloonan, S. A., Taylor, E. C., \& Dailey, N. S. (2021). Mental health during the first weeks of the COVID-19 pandemic in the United States. Front Psychiatry, 12, 561898. https://doi.org/10.3389/fpsyt.2021.561898

Kim, D.-Y., \& Phillips, S. W. (2021). When COVID-19 and guns meet: A rise in shootings. Journal of Criminal Justice. https://doi.org/ 10.1016/j.jcrimjus.2021.101783

Lisciandrello, C. (2020). Florida's reopening in Phase 3: What does it mean? Health News Florida. Retrieved June 7 from https:// health.wusf.usf.edu/health-news-florida/2020-09-27/floridasreopening-in-phase-3-what-does-it-mean

Lopez, E., \& Rosenfeld, R. (2021). Crime, quarantine, and the U.S. coronavirus pandemic. Criminology \& Public Policy, 20(3), 401422. https://doi.org/10.1111/1745-9133.12557

Markel, H. (2020). Analysis: Why some schools stayed open during the 1918 flu pandemic. PBS News Hour. Retrieved July 26 from https://www.pbs.org/newshour/health/analysis-why-some-schoo 1s-stayed-open-during-the-1918-flu-pandemic

Mohler, G., Bertozzi, A. L., Carter, J., Short, M. B., Sledge, D., Tita, G. E., Uchida, C. D., \& Brantingham, P. J. (2020). Impact of social distancing during COVID-19 pandemic on crime in Los Angeles and Indianapolis. Journal of Criminal Justice. https://doi.org/10. 1016/j.jcrimjus.2020.101692

Nix, J., \& Richards, T. N. (2021). The immediate and long-term effects of COVID-19 stay-at-home orders on domestic violence calls for service across six U.S. jurisdictions. Police Practice \& Research, 22(4), 1443-1451. https://doi.org/10.1080/15614263.2021.18830 18

Ojimba, C., Tumenta, T., Thanju, A., Oforeh, K., Osaji, J., Saha, A., \& Valbrun, L. (2020). COVID-19 pandemic and uptake in suicide attempt among young people of minority population: A case series. Journal of Medical Case Reports, 11(12), 411-416. https:// doi.org/10.14740/jmc3594

Piquero, A., Jennings, W., Jemison, E., Kaukinen, C., \& Knaul, F. (2021). Domestic violence during the COVID-19 pandemic: Evidence from a systematic review and meta-analysis. Journal of Criminal Justice. https://doi.org/10.1016/j.jcrimjus.2021.101806

Piquero, A., Piquero, N. L., \& Kurland, J. (2021). A case study of domestic violence arrests during the COVID-19 pandemic in Miami-Dade County. Victims \& Offenders, 16(8), 1077-1088.

Piquero, A. R., Riddell, J. R., Bishopp, S. A., Narvey, C., Reid, J. A., \& Piquero, N. L. (2020). Staying home, staying safe? A short-term analysis of COVID-19 on Dallas domestic violence. American Journal of Criminal Justice, 45(4), 601-635. https://doi.org/10. 1007/s12103-020-09531-7

Reingle Gonzalez, J. M., Molsberry, R., Maskaly, J., \& Jetelina, K. K. (2020). Trends in family violence are not causally associated with COVID-19 stay-at-home orders: a commentary on Piquero et al. In (Vol. 45, pp. 1100-1110).

Sloan, M., Haner, M., Graham, A., Cullen, F., Pickett, J., \& Lero Jonson, C. (2021). Pandemic emotions: the extent, correlates, and mental health consequences of fear of COVID-19. Sociological Spectrum, 41(5), 369-386. https://doi.org/10.1080/02732173. 2021.1926380

Speck, E. (2020). Florida is now under a statewide stay-at-home order. Here's what it means (clickorlando.com, Issue). https://www.click orlando.com/news/local/2020/04/01/florida-will-soon-be-under-astatewide-stay-at-home-order-heres-what-it-means/

State of Florida. (2020). Office of the governor executive order number 20-91. State of Florida. https://www.flgov.com/wp-content/uploa ds/orders/2020/EO_20-91-compressed.pdf

Stern, A. M., Cetron, M., \& Market, H. (2010). The 1918-1919 influenza pandemic in the United States: Lessons learned and challenges exposed. Public Health Report, 125, 6-8. 
Stickle, B. (2020). Package theft in a pandemic. https://www.ucl.ac.uk/ jill-dando-institute/sites/jill-dando_ institute/files/package_theft_ in_a_pandemic_final_no_15_.pdf.

Stickle, B., \& Felson, M. (2020). Crime rates in a pandemic: The largest criminological experiment in history. American Journal of Criminal Justice, 45(4), 525-536. https://doi.org/10.1007/ s12103-020-09546-0

Sunderland, K. (2020). Timeline: How coronavirus pandemic developed in Florida over last 6 months. wfla.com. Retrieved May 18 from https://www.wfla.com/news/by-the-numbers/timeline-howmuch-has-coronavirus-spread-through-florida-in-last-6-months/

Tsamakis, K., Tsiptsios, D., Ouranidis, A., Mueller, C., Schizas, D., Terniotis, C., Nikolakakis, N., Tyros, G., Kympouropoulos, S., Lazariss, A., Spandidos, D. A., Smyrnis, N., \& Rizos, E. (2021). COVID-19 and its consequences on mental health (Review). Experimental and Therapeutic Medicine, 21(3), 244. https://doi. org/10.3892/etm.2021.9675

Viero, A., Barbara, G., Montisci, M., Kustermann, K., \& Cattaneo, C. (2021). Violence against women in the Covid-19 pandemic: A review of the literature and a call for shared strategies to tackle health and social emergencies. Forensic Science International. https://doi.org/10.1016/j.forsciint.2020.110650

Walker, J. T. (2021). Ecological fallacy. In C. Barnes \& D. R. Forde (Eds.), The encyclopedia of research methods in criminology and criminal justice. Wiley Online Library. https://doi.org/10.1002/ 9781119111931.ch98

Walton, J. (2019, May 8, 2019). Florida's economy: The 6 industries driving GDP grown. Retrieved July 26 from https://www.inves topedia.com/articles/investing/011316/floridas-economy-6-indus tries-driving-gdp-growth.asp

Wasserstein, R. L., \& Lazar, N. A. (2016). The ASA statement on p-values: Context, process, and purpose. The American Statistician, 70(2), 129-133.

WFLA Staff. (2020). Phase 1 of reopening Florida begins. News Channel 8. Retrieved June 7 from https://www.wfla.com/news/florida/ phase-1-of-reopening-florida-begins/

Winchester, J. (2021, August 10, 2021). Big business, schools defy DeSantis' orders. WINK Digital Media. https://www.winknews. com/2021/08/09/big-business-schools-defy-desantis-orders/ 